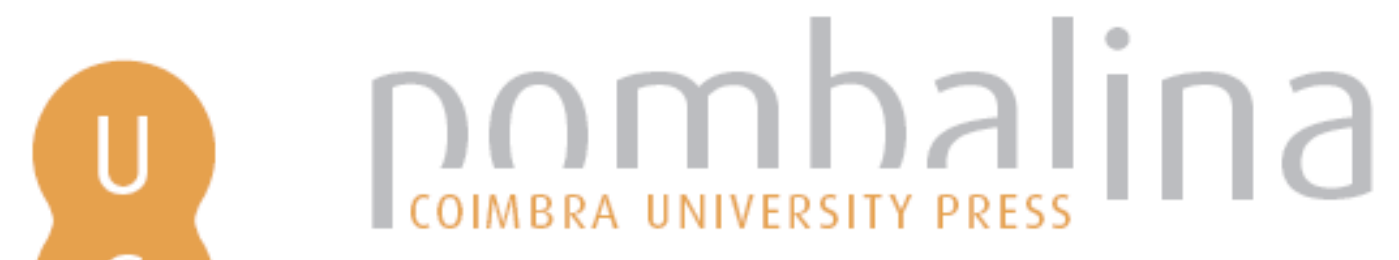

\title{
Vias de água, paisagens: a noção de património fluvial
}

\author{
Autor(es): $\quad$ Peyret, Pierre
}

Publicado por: Imprensa da Universidade de Coimbra

URL

persistente: URI:http://hdl.handle.net/10316.2/39317

DOI: $\quad$ DOI:http://dx.doi.org/10.14195/978-989-26-1025-2_2

Accessed : $\quad$ 26-Apr-2023 16:22:16

A navegação consulta e descarregamento dos títulos inseridos nas Bibliotecas Digitais UC Digitalis, UC Pombalina e UC Impactum, pressupõem a aceitação plena e sem reservas dos Termos e Condições de Uso destas Bibliotecas Digitais, disponíveis em https://digitalis.uc.pt/pt-pt/termos.

Conforme exposto nos referidos Termos e Condições de Uso, o descarregamento de títulos de acesso restrito requer uma licença válida de autorização devendo o utilizador aceder ao(s) documento(s) a partir de um endereço de IP da instituição detentora da supramencionada licença.

Ao utilizador é apenas permitido o descarregamento para uso pessoal, pelo que o emprego do(s) título(s) descarregado(s) para outro fim, designadamente comercial, carece de autorização do respetivo autor ou editor da obra.

Na medida em que todas as obras da UC Digitalis se encontram protegidas pelo Código do Direito de Autor e Direitos Conexos e demais legislação aplicável, toda a cópia, parcial ou total, deste documento, nos casos em que é legalmente admitida, deverá conter ou fazer-se acompanhar por este aviso.

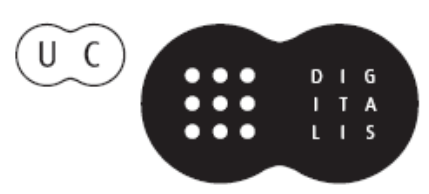




\section{VIAS DE ÁGUA, PAISAGENS: A NOÇÃO DE PATRIMÓNIO FLUVIAL}

PIERRE PEYRET 


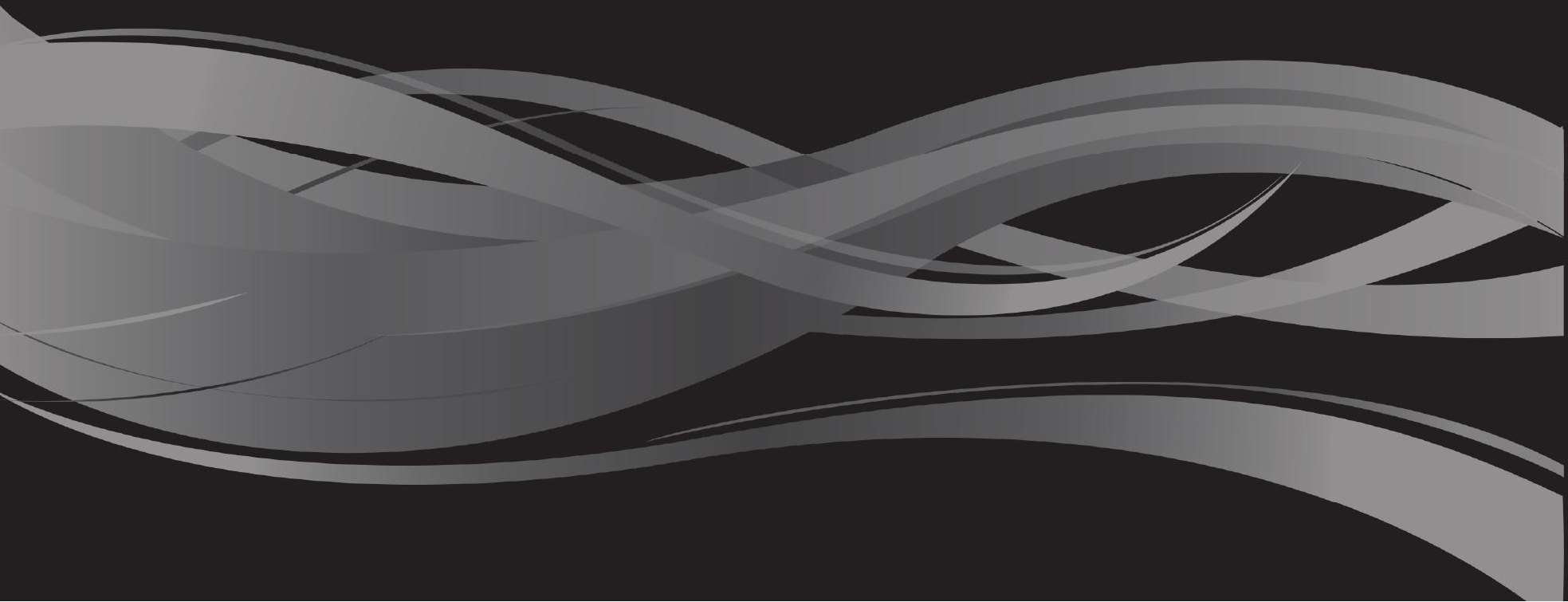


Evocar as vias de água é, antes de mais, evocar a diversidade. Espaços fechados, espaços abertos, planos de água interiores, planos de água naturais ou artificiais, águas estagnadas, águas vivas, livres.

O rio, a ribeira, a torrente, o riacho, o canal, ou melhor dizendo os canais: de irrigação, de junção, laterais. É evocar ao mesmo tempo a substância líquida e a sua antropização, "a natureza" e o artificial; é evocar vetores de um recurso vital, meios frágeis, um formidável reservatório de vida vegetal e animal, o próprio símbolo do movimento, uma massa que, devido a um desnível, corre num leito de montante para jusante. Aceleração, abrandamento, lentidão e impetuosidade.

É evocar também os diversos usos; diversos ao longo do tempo. É evocar ainda significados plurais e diversos. O vertical e o horizontal, um espaço de três dimensões. É evocar paisagens; é evocar técnicas de dominação hidráulica, um motor económico. É a tinta e o pincel. É a ambivalência entre prazer e necessidade. Mística, utilitária, onírica, ameaçadora. Atração, repulsa. É a ruptura e a sutura, o obstáculo e a ligação. Curva, contra-curva, retidão. A água e a sua margem, a linearidade e a transversalidade.

É evocar a longa cavalgada da água agregando-se à água e desagregando-se do cascalho. São dois corpos físicos, a água e a terra, coniventes e antagónicos, dois códigos controlados de forma diferente pela duplicidade da lei, estática para um e dinâmica para outro, duas formas de sujeição, duas incompatibilidades eternas, a água e a sua orla. É um trabalho de ligação perpétua, a água e a sua cercadura procurando as suas unidades, colmatando-se; um sistema binário susceptível de distorções, em que cada elemento procura constantemente libertar-se do outro. A água traz em si a imagem mais espetacular, a imagem do movimento à procura da sua libertação. É a terra que opera a repressão que enquadra, enquanto a água dá forma lutando contra o centralizado, o geometrizável, assombrado por uma axiomática da fuga e da expansão.

É a axiomática da fuga e da expansão contra a repressão; é a imobilidade e a mobilidade que se enfrentam; é a transparência e a opacidade. A água transparente, a água espelho. São dois elementos essenciais mas que tudo parece separar mas é também a complementaridade e a interdependência, o campo e o contra campo.

Dois corpos monárquicos, constituídos. É a linha de separação entre a norma e os seus desvios.

São tecnologias que tratam estes corpos como máquinas, técnicas agenciadas com vista a um rendimento que sistematize e racionalize as suas formas fundamentais. É evocar o estabelecimento das comunidades humanas, o eixo estruturante dos vales, o eixo de desenvolvimento de atividades, um eixo de descoberta. Realidades físicas, princípios históricos, caminhos de filiação, escritura do tempo. São diferentes espaços, dimensões, escalas. Noções de contextos, contextos físicos, contextos de enunciação, práticas, hábitos, culturas locais peculiares, específicas, zonas de intervenção, por vezes limitadas mas sempre complexas, é uma forma de definição sujeita ao relativismo, é uma pluralidade de discursos que têm dificuldades de convergir.

\section{Paisagens - A visão europeia da paisagem}

A Convenção Europeia da Paisagem adotada em Florença, em Itália, a 20 de outubro de 2000, tem por objetivo promover a proteção, a gestão e o ordenamento das paisagens europeias e organizar 
a cooperação europeia neste domínio. Considerada como a primeira convenção do desenvolvimento sustentável, representa um importante contributo na operacionalização dos objetivos do Conselho da Europa: trata-se de favorecer a qualidade de vida e o bem estar individual e social tendo em conta os valores paisagísticos, naturais e culturais.

Os Estados membros da Organização signatários da Convenção declararam-se preocupados em "chegar a um desenvolvimento sustentável fundado no equilíbrio harmonioso entre as necessidades sociais, a economia e o ambiente". A dimensão cultural ocupa igualmente um lugar central.

Instrumento inovador, a Convenção representa um tratado internacional exclusivamente dedicado ao conjunto da Paisagem dos Estados Europeus, considerado como espaço de vida dos indivíduos e das sociedades. Cada uma das partes contratante se compromete a reconhecer juridicamente a paisagem enquanto componente essencial do quadro de vida das populações, expressão da diversidade do seu património comum cultural e natural, e fundamento da sua identidade.

A Convenção Europeia da Paisagem define a paisagem do seguinte modo: a paisagem é "uma parte de território tal como é percecionada pelas populações, cujo caráter resulta da ação de fatores naturais e/ou humanos e das suas interelações". É salientado que a política da paisagem é "a formulação, pelas autoridades públicas competentes, dos princípios gerais, das estratégias e das orientações que permitem a adoção de medidas particulares com vista à projeção, gestão e ordenamento da paisagem".

Encontramos aqui ao mesmo tempo o impacto da corrente fenomenológica e da abordagem sistémica.

Madame Maguelone Déjeant Pons, Chefe de Divisão do património cultural da paisagem e do ordenamento do território no Conselho da Europa, lembrava aliás, na sua intervenção sobre a paisagem fluvial por ocasião do $7^{\circ}$ Colóquio Fluvial Europeu do Sul, em Sevilha, que:

"as bacias fluviais e os vales aluviais representam um desafio específico para o ordenamento do território porque estão concentrados em bandas de território relativamente estreitas caracterizadas simultaneamente por elementos naturais importantes e de grande valor e por atividades humanas diversas".

Salienta ainda que "se reconhece tratar-se frequentemente de paisagens que tomaram forma ao longo dos séculos e detêm um potencial económico e ecológico considerável".

Uma das características da paisagem é pois o seu aspeto construtivo evolutivo, orientando a sua compreensão em função da sua relação com a história social, implicando tensão e, por vezes, mesmo contradição. A paisagem é ao mesmo tempo condicionada pela sua natureza inicial que determina mais ou menos uma forma de autonomia da sua forma e a sua imbricação com a história social que deu origem a transformações. É um tempo não uniforme, ligado a vidas, com termos e descontinuidades, um tempo humanizado. A paisagem possui a sua própria dinâmica; dinâmica essa ligada à sua transformação e aos valores do território com o qual está relacionada. As múltiplas atualizações da sua evolução.

Deve portanto apreender-se a paisagem de acordo com o seu duplo valor: valor intrínseco e valor extrínseco. A outra característica é a sua espacialidade, a entidade paisagística. Característica que se refere não apenas à profundidade do campo visual, ao seu limite topográfico mas também ao modelo 
antropológico através da teoria de quem olha como construção social, gerando a relação materialidade/ cultura, na qual podemos reconhecer a oposição, a contradição.

São ao mesmo tempo características de representações e de experiências de territórios, relações da estética e do utilitarismo. A conciliação da natureza e da vida realizou-se na paisagem através das representações geradas pelas dinâmicas económicas e pelas práticas sociais. Ao mesmo tempo materialidade e imaterialidade. Ao estabelecer a relação da paisagem com os usos que dela se fazem, a imaterialidade, as dimensões imateriais do património adquirem a sua dimensão material: trama urbana, património imobiliário.

\section{A noção de património fluvial}

Definir o que está englobado na noção de património fluvial implica, antes de mais, tomar como primeira referência a Convenção do Património Mundial que, no artigo 1, define um património cultural como sendo "obras do homem ou obras conjugadas do homem e da natureza tais como zonas, incluindo sítios arqueológicos, que possuem valores universais excecionais do ponto de vista histórico, estético, etnológico ou antropológico.".

Herveline Delhumeau, assessora para o Património Marítimo e Fluvial do Ministério da Cultura e da Communicação francês salienta que "a identidade do domínio fluvial é um conjunto cultural coerente, de montante a jusante, indissociável de todos os aspetos patrimoniais que o caracterizam: património natural e cultural, material, imobiliário, mobiliário mas também imaterial".

Daí resulta, pelo menos, que as paisagens fluviais podem ser definidas não apenas à escala do rio, mas antes à escala do vale da via de água, o talvegue dos geógrafos, quer se trate de um rio, de uma ribeira, de um canal, de um canal de junção ..., a escala na qual o rio ou o canal intervieram, em vez de estabelecer um parcelamento de facto ligado ao campo visual ou a dimensões administrativas ou políticas locais.

Os cursos de água foram elementos estruturantes de todas as paisagens, dos eixos vivos cuja inscrição no espaço é sempre forte.

E isso pode ser ainda mais significativo no caso de um canal, o corredor do canal constitui um conjunto coerente embora secante no sentido geográfico: a via navegável e o terreno de reserva do canal formam uma espinha dorsal ao longo da qual foram implantadas e evoluíram numerosas atividades humanas, industriais.

Estas duas componentes são indissociáveis e essenciais para a compreensão da noção de paisagem fluvial.

A paisagem fluvial pode ser considerada como um espaço de água, um espaço ligado à água inscrito numa duração temporal que tem origem na geografia física de um lugar, de um sítio, mas cuja apropriação pelo ser humano, ou mesmo a conquista desse espaço a uma dada escala, transformou esse espaço físico para nele construir o seu lugar de vida, o seu quadro de vida, o seu quotidiano. 
De um certo modo, o espaço tornou-se testemunho das vivências do ser humano, um elemento significante da sua história. É um lugar de inscrição do passado, das práticas, dos hábitos ligados aos seres vivos marcados na matéria, no conjunto dos elementos naturais.

É uma espécie de estratificação socioeconómica de um lugar físico inicial.

A noção de paisagem implica uma diversidade dos campos disciplinares (geografia, naturalista, agronomia, história, arquitetura, urbanismo) que, para lá das formas visíveis, permitem compreender a diversidade e a unidade, de entender a complexidade: trata-se de transdisciplinaridade mais do que de multidisciplinaridade ou interdisciplinaridade.

\section{Cidades de água e paisagens fluviais}

Qualquer que seja a implantação das cidades molhadas: cidades vaus, cidades porto, cidades instaladas em pontos de rutura da navegação interior ..., as cidades antigas organizaram-se em relação aos cursos de água, à presença da água, sede de uma atividade intensa, as ruas estabeleceram-se perpendicularmente às margens, os principais mercados desenvolveram-se frequentemente à beira, a bordo dos batéis. Mas o rio na cidade é também os banhos públicos, os lavadouros, os bebedouros, os moinhos naves, a pesca, o passeio, os jogos e as festas na água.

A transformação da fisionomia das paisagens hidráulicas urbanas ilustra perfeitamente a evolução do uso da água ligada às múltiplas reconversões e evoluções sucessivas, desde as adaptações antigas até às atividades industriais e às técnicas de produção.

A via de água era um bem precioso útil como elemento físico necessário, entre outras coisas, para a lavagem e desengurdoramento das lãs e dos couros, ao tingimento de peças de tecido, ao branqueamento de telas.... Era útil como fonte de energia, acionando os moinhos, as fábricas de fiação ou as fábricas hidráulicas, útil como meio de navegação de madeiras flutuadas, de navios para transporte de mercadorias, de matérias primas, de produtos industriais, de pessoas. A via de água desempenhou um papel no fornecimento de água às cidades (estações elevatórias), na irrigação de terrenos agrícolas que alimentavam essas mesmas cidades, assegurando os recursos haliêuticos. Todas estas práticas são, a maior parte das vezes, antagónicas. A fisionomia das paisagens hidráulicas vai evoluir segundo a evolução das relações de força entre os diversos utilizadores, o que hoje denominamos de conflitos de uso, a luta pela sua apropriação, os diferentes usos inscrevem-se na forma urbana.

Esta herança da presença da água na cidade, esta estratificação da evolução dos usos releva frequentemente mais do património urbano do que do património arquitetónico.

Os edifícios raramente têm ou não têm de todo uma linguagem arquitetónica que os distingue dos outros edifícios. Pelo contrário, a trama parcelar, a escala do espaço público, o cruzamento das ruas e dos braços de rios ou de canais - isto é, a expressão física dos usos, dos direitos de água, dos acessos à água muitas vezes dificilmente adquiridos pelo utente ou proprietário ribeirinho - materializa com frequência as raízes profundas da identidade urbana das cidades de água. 
A adaptação que as realizou já não se exprime no presente, são adaptações desafetadas.

O quadro do projeto define uma espacialidade confinada ao urbano. Sem no entanto decidir se existe uma experiência da água irredutível ligada à cidade, fica claro que existe um laço muito forte entre vários aspetos: a água enquanto património, a água enquanto componente da paisagem urbana, a água como forma de divertimento, presença da água enquanto uso e um lugar específico, a cidade, quer se lhe atribua um estatuto teórico ou não.

Existe na água como património da cidade uma realidade temporal absolutamente fundamental, mesmo quando as distensões temporais de usos são por vezes consideráveis. Foi a estrutura de uso que impôs um certo tipo de qualificação e que produz as formas de continuidade plural e polissémica, associando valores tradicionais às ideias de natureza, património construído, identidade local, quadro de vida, desenvolvimento económico.

É também, por vezes, uma utilização de algo que pertence à natureza num quadro que tende, no fim de contas, para o instrumental.

É ainda necessário integrar a questão dos lugares. É evidente que o desaparecimento dos usos tradicionais da água define uma nova periodização que é preciso ter em conta e que corresponde a um novo tipo de formatação, visto que a água como património é um instrumento de formatação, uma prática um pouco indecisa entre valores tradicionais e preocupações contemporâneas de qualidade de vida em que ela serve de linha de triagem. Temos ainda a inclusão da água na requalificação da paisagem urbana, paisagem essa que se constitui como lugar de exposição, toda uma série de transformações extremamente importantes e entre elas esta difusão de formas da água móvel em água artificialmente móvel, em água estagnada e, por vezes, em água revolta.

O desafio colocado pela água na cidade é o de encontrar um modo de concordância entre todas estas transformações, se não quisermos cair nos esquemas do tipo triunfo e morte da água viva, estetização ou anestetização ...

O trabalho sobre a noção de bem material e imaterial coloca a questão de pensar as formas da apropriação cultural.

Partilha de novos usos que geram apropriação e noções de cultura. Tudo começa com o facto de se considerar ora a existência de uma única ou de várias culturas urbanas, o que implica noções de fronteiras mais ou menos definidas, ora a formação de uma nova cultura mediante a integração de uma série de formas e procedimentos.

A problemática consiste em definir uma especificidade das cidades molhadas e de fazer valer essa especificidade porque um referenciamento não é uma identidade.

\section{A reabilitação}

A reabilitação subentende a proteção da característica da espacialidade da paisagem que deve incidir sobre a imaterialidade dos lugares, enquanto que a proteção das representações engendradas 
por uma dinâmica económica e por práticas sociais incide sobre a sua dimensão material, trama urbana, património imobiliário.

Os aspetos atuais dos bairros com relação à via de água hipotecam a conservação da trama das ruas e do tecido urbano. É ainda importante lembrar que o valor patrimonial de um bem imobiliário também se encontra na relação das pessoas com o lugar (os usos, por exemplo) ou ainda no aspeto afetivo ou simbólico que a população tem com o lugar. O modo traumático da destruição já não é habitual, como também já não faz sentido a preservação absoluta, reenviando para medidas normativas que tinham como consequência fixar um território no tempo. A noção atual inscreve-se antes na proteção ou valorização deixando esses patrimónios evoluir no interior de um quadro capaz de impedir as mutações irreversíveis da sua identidade. O centro desta proteção é a manutenção dos usos que asseguram a expressão reconhecida dos lugares, estando esses usos geralmente ligados a um tipo de economia, manutenção que está na origem da expressão cultural e social dessa paisagem. O facto de relacionar a paisagem fluvial com os usos interpela diretamente a imaterialidade dos lugares. Nesse sentido, a paisagem fluvial associa-se em parte às dimensões imateriais do património.

A persistência fantasma, o modo dessincronizado que essa paisagem inventa a partir das sobrevivências de formas antigas, mantem, ao mesmo tempo que empreende, uma criação ancorada em diferentes tempos. Falar da água como património é ler a água em todas as suas dimensões.

Falar de paisagem fluvial é admitir também a ideia de olhar para as margens a partir da água, o que equivale, mais uma vez, a uma abordagem histórica, dado que numerosos territórios foram descobertos graças à via de água enquanto suporte à deslocação. Aceitar esta ideia significa não se fechar na abordagem conhecida que consiste em apreender a água a partir da terra, aceitando ao mesmo tempo o contra campo da "imersão", o que pressupõe que se trata de um olhar forçosamente diferente.

Um ângulo de abordagem limitado, um fragmento extraído, subtraído à sua realidade: uma pausa ou um intervalo azul ou verde na mineralidade da cidade tornam-se insignificantes, enquanto que uma pausa apreendida, vivida do interior e não como adereço, torna-se significante.

Trata-se de conhecer a via de água pelo seu timbre, pela sua corrente, pelas suas profundezas, pelas suas cheias e pelos seus limites. É a outra vertente das coisas; é, na realidade, habitar a água como se habita as margens, não apenas pelo sentido de se alojar mas também pela possibilidade de se manter numa superfície diferente e apreender a cidade a partir da água, um campo bidirecional que permite ver para além da margem que fica em frente. Trata-se de substituir uma visão horizontal por uma visão vertical ou uma abordagem vertical, um grau de comprometimento que toma em consideração a existência da água na cidade. É aceitar que a água não está confinada a um espaço fechado, aceitar as suas virtudes e as suas variações. Iniciar uma reflexão sobre a água como património ligado ao urbano só pode levar a valorizar os méritos da água, aceitando que essa água não é frígida, distante, intocável, pois isso seria reduzir a água a um papel decorativo, a um objeto instrumentalizado, um simples valor estético passageiro. Ora, uma abordagem séria implica que a água deve ser viva e devemos aceitá-la como matéria viva, compreender a sua cor mutante, 
entrever os seus movimentos, estabelecer uma coabitação prolongada, levando em conta as suas realidades profundas, intrínsecas.

Obra única no seu género, obra global na qual se inscreveriam com naturalidade várias animações, várias ações cada uma delas em lugar de destaque, cada uma constituindo uma parte de um conjunto significativo e equilibrado, espaço harmónico como sugere Fourrier.

Trata-se de adotar uma reflexão em que o rio não é apenas visto como um valor ou como tendo uma função cognitiva.

Parece certamente legítimo debater e tentar avaliar a plausibilidade dos laços que poderiam unir o rio e a cidade. Já não se trata de desconstruir nem de evocar as brumas inefáveis do tempo mas antes de tentar reconstruir a criação, de reconstruir a relação a partir dos fragmentos ainda dispersos.

Qualquer reflexão deve ser tomada não como um ponto de chegada mas como uma proposta a desenvolver, uma pesquisa que se faz aceitando que está sujeita a um constante devir evolutivo.

A palavra compreender, cuja raiz clássica se encontra no latim comprendere, termo resultante da síncope da palavra latina comprehendere, cum (com) e prehender (agarrar), de acordo com o dicionário Littré, possui o sentido de apreender em conjunto fisicamente. A disjunção que leva a conceber a água associada ao prazer de contemplar, de se distrair do quotidiano, ao descanso, ao bem-estar, à humanização da vida, ao ganho de um complemento de felicidade, é uma abordagem que não permite reunir o que a experiência proposta dissocia.

Ao mesmo tempo, captação e reflexão global autêntica, compreensão da parte pelo todo e do todo pela parte. Trata-se de aceder ao sentido e não de adquirir nem de atribuir um sentido. É preciso tratar a história, o lugar, a via de água, alternando entre a representação do real e representação das ideias.

É tanto a identificação dos detalhes significantes como a perceção das relações globais.

É tomar em consideração a distinção de múltiplos níveis de integração hierárquicos encaixados uns nos outros aos quais se ligam de modo causal as funções definidas, uma combinatória da estrutura e da função.

A transição de um uso, de um nível de organização para outro, encontra a sua solução nos múltiplos processos de evolução imbricados uns nos outros, tanto no espaço como no tempo.

Refletir sobre a posição da água na cidade é aceitar a ideia de um movimento de abertura baseado no enriquecimento dos reportórios: reportório da água e reportório da cidade no que se refere aos contactos entre ambas as entidades, reportórios especializados ou não.

Um dos meios para levar a cabo esta tarefa passa talvez por reconstruir uma função hierarquicamente mais elevada a partir dos elementos e determinar o modo como esses mesmos elementos interagem entre eles para definir, para aceder a uma verdadeira função emergente. É uma nova inscrição. Inscrição que permite investir em todas as promessas que o testemunho do passado, realidade física e simbólica, permitirá realizar.

Trata-se de colocar nesta abordagem todo o património reunido das práticas, de entender este conjunto como um receptáculo: a cidade de água da qual um conjunto de propriedades seria 
o conteúdo. O património age sobre si próprio; se não sobre o seu ser, age pelo menos sobre o seu desenvolvimento. É o instante real e a duração pensada, o conceito e a construção.

Entender a água como património é talvez conceber o património como um ato restituído à sua novidade. É pois o ato de captar este estado no seu crescimento para o captar na sua essência. Entender a água como património é também, pelo seu incremento de sucesso, promover a síntese da novidade e do traço/rasto. 